\title{
Host Effect on the Molecular and Biological Properties of a Citrus exocortis viroid Isolate from Vicia faba
}

\author{
Mónica Gandía, Lucía Bernad, Luis Rubio, and Núria Duran-Vila
}

Departamento de Protección Vegetal y Biotecnología. Instituto Valenciano de Investigaciones Agrarias (IVIA), Apartado oficial, 46113 Moncada (Valencia) Spain.

Accepted for publication 29 March 2007.

\begin{abstract}
Gandía, M., Bernad, L., Rubio, L., and Duran-Vila, N. 2007. Host effect on the molecular and biological properties of a Citrus exocortis viroid isolate from Vicia faba. Phytopathology 97:1004-1010.

Citrus exocortis viroid (CEVd) is the casual agent of citrus exocortis disease, and has been found in naturally infected citrus and noncitrus hosts. Field isolates of CEVd may infect susceptible hosts as a complex of genetically related sequence variants (haplotypes). In the present work, a CEVd isolate recovered from a symptomless broad bean plant was characterized as a heterogeneous population with a nucleotide diversity of 0.026 , which did not contain a predominant haplotype. When nucleic acid

extracts of this infected broad bean were used to inoculate tomato, the plants displayed symptoms and the CEVd population was more homogeneous, with a nucleotide diversity of 0.007 . However, when nucleic acid extracts from this tomato isolate were back inoculated to new broad bean plants, this isolate did not revert to the original population, because it showed low nucleotide diversity $(0.001)$ and induced symptoms in the broad bean plants. Symptomless broad bean plants may act as reservoirs of highly heterogeneous populations of CEVd variants, providing an excellent inoculum source in terms of its potential to infect a broad range of putative hosts. The epidemiological implications are discussed.
\end{abstract}

Citrus exocortis viroid (CEVd) is the casual agent of citrus exocortis (29), a disease characterized by bark scaling symptoms in susceptible citrus hosts. CEVd has a wide experimental host range that includes sensitive and tolerant species. CEVd also has been found naturally, occurring in noncitrus hosts such as tomato, grapevine, eggplant, turnip, and carrot $(5,8,10,15)$. Using tomato as an experimental host and taking into account biological properties, Visvader and Symons (34) proposed a classification of CEVd sequences into severe "class A" and mild "class B" which differ by a minimum of 26 nucleotides, mainly affecting the $P_{L}$ and $P_{R}$ regions located in the pathogenicity $(\mathrm{P})$ and variable $(\mathrm{V})$ domains, respectively, of the viroid secondary structure.

During a survey conducted in vegetable crops grown in eastern Spain, CEVd was identified in symptomless broad bean (Vicia faba L.) plants (6). This CEVd isolate was present in very low titers in the infected broad bean plants, but reached high titers in inoculated tomato plants, which unexpectedly remained symptomless. However, broad bean seedlings inoculated with extracts from the CEVd-infected symptomless tomato plants became stunted, had shorter internodes than the noninoculated controls, and contained viroid titers comparable with those normally found in tomato. The consensus sequences of (i) CEVd-i, the CEVd isolate recovered from the initial source (broad bean); (ii) CEVd-t, the CEVd recovered from the inoculated tomato plants (broad bean $\rightarrow$ tomato); and (iii) CEVd-f, the CEVd from broad bean inoculated with CEVd-t (broad bean $\rightarrow$ tomato $\rightarrow$ broad bean) differed from each other and resulted in major changes in replication efficiency, host range, and pathogenicity (6). These results showed that the molecular and biological properties of the broad

Corresponding author: N. Duran-Vila; E-mail address: nduran@ivia.es

Accession numbers of CEVd-i population, EF488049 to EF488068; CEVd-t population, EF494683 to EF494697; and CEVd-f population, EF494677 to EF494682.

doi:10.1094/PHYTO-97-8-1004

(C) 2007 The American Phytopathological Society bean CEVd isolate were modified after passage through alternate hosts.

CEVd, like genomes of other RNA pathogens, has been shown to be present in inoculated citron plants (Citrus medica L.) as populations of closely related sequences which, unlike other RNA genomes, present a low nucleotide diversity (9). Preliminary studies showed that the host may affect the genetic variability of CEVd (3). Therefore, in order to understand the evolution of CEVd-i after passage through an alternate host, it is essential to know the genetic structure of the viroid population and the changes associated with the generation of CEVd populations having distinct replication efficiencies and biological properties. The present work describes the population structure of CEVd-i, CEVd-t, and CEVd-f and the de novo generation of populations derived from infection with a selection of single sequence variants from $\mathrm{CEVd}$ $\mathrm{i}$ and CEVd-f isolates.

\section{MATERIALS AND METHODS}

Viroid sources and extraction procedure. Nucleic acid preparations from broad bean $(\mathrm{CEVd}-\mathrm{i}$ and $\mathrm{CEVd}-\mathrm{f})$ were used to inoculate broad bean cv. Muchamiel seedlings. Inoculated and noninoculated plants were kept in a greenhouse at $25^{\circ} \mathrm{C}$ for at least 3 months before being used as a source of tissue. CEVd-i was the preparation obtained from the field broad bean source (6), CEVd-t was recovered from inoculated tomato (broad bean $\rightarrow$ tomato) (6), and CEVd-f was recovered from inoculated broad bean plants with tomato extracts (broad bean $\rightarrow$ tomato $\rightarrow$ broad bean) (6). Samples (5 g) of young leaves and stems were homogenized in a 5-ml volume of extraction buffer $(0.4 \mathrm{M}$ Tris- $\mathrm{HCl}$, $\mathrm{pH} 8.9 ; 1 \%[\mathrm{wt} / \mathrm{vol}]$ sodium dodecyl sulfate [SDS]; 5 mM EDTA,

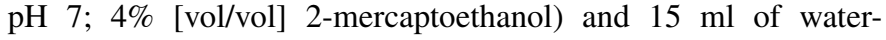
saturated phenol (27). The total nucleic acids were partitioned in $2 \mathrm{M} \mathrm{LiCl}$ and the soluble fraction was precipitated and resuspended in TKM buffer $(10 \mathrm{mM}$ Tris- $\mathrm{HCl}, 10 \mathrm{mM} \mathrm{KCl}$, and $0.1 \mathrm{mM} \mathrm{MgCl}_{2}, \mathrm{pH}$ 7.4). These preparations were used for sequential polyacrylamide gel electrophoresis (sPAGE) and 
northern blot hybridization analysis, or as a source of inoculum.

Viroid analysis. Aliquots of the nucleic acid preparations (equivalent to $300 \mu \mathrm{g}$ of fresh weight tissue) were subjected to sPAGE. Briefly, the samples were subjected to a 5\% nondenaturing PAGE at $60 \mathrm{~mA}$ for $2.5 \mathrm{~h}$ (17). A segment of the ethidium-bromide-stained gel containing CEVd and 7S RNA was subjected to a second PAGE containing $8 \mathrm{M}$ urea at $18 \mathrm{~mA}$ for $4 \mathrm{~h}$ $(22,26)$. Viroid bands were visualized by silver staining (12).

For northern blot hybridization, the nucleic acids were electrotransferred from the second gel to positively charged Nylon membranes (Roche) at $200 \mathrm{~mA}$ for $1 \mathrm{~h}$ using modified TBE buffer (40 mM Tris, $40 \mathrm{mM}$ boric acid, and $1 \mathrm{mM}$ EDTA, pH 8.3). The membranes were UV cross-linked and hybridized with a digoxigenin (DIG)-labeled CEVd probe. DIG-labeled DNA-CEVd probes were synthesized by polymerase chain reaction (PCR) using a pCEVd plasmid as template (21). Prehybridization and hybridization were performed in 50\% formamide and 6× SSPE (1× SSPE is $0.18 \mathrm{M} \mathrm{NaCl}, 10 \mathrm{mM} \mathrm{NaPO} 4$, and $1 \mathrm{~nm}$ EDTA [pH 7.7]) as described by Sambrook et al. (25). The membrane was prehybridized at $42^{\circ} \mathrm{C}$ for 2 to $4 \mathrm{~h}$ and hybridized overnight at $50^{\circ} \mathrm{C}$. After hybridization, it was washed twice in $2 \times \mathrm{SSC},(1 \times$ $\mathrm{SSC}$ is $0.15 \mathrm{M} \mathrm{NaCl}$ plus $0.015 \mathrm{M}$ sodium citrate) and $0.1 \%$ SDS at room temperature for $15 \mathrm{~min}$, followed by another wash in $0.1 \times$ SSC and $0.1 \%$ SDS for $60 \mathrm{~min}$ at $60^{\circ} \mathrm{C}$. The DIG-labeled hybrids were detected with an anti-DIG phosphatase conjugate (Fab fragments) and visualized with the chemiluminescence substrate CSPD (Roche).

cDNA synthesis and cloning. Aliquots of the nucleic acid preparations of CEVd-i, CEVd-t, and CEVd-f were subjected to SPAGE. The denaturing gel was stained with ethidium bromide and the circular forms of the viroid were purified with a volume of elution buffer ( $0.1 \mathrm{M}$ Tris- $\mathrm{HCl}, \mathrm{pH} 8.9$, containing $1 \mathrm{mM}$ EDTA and $0.1 \%$ SDS) and a volume of phenol/chloroform/ isoamyl alcohol (25:24:1). The RNA was recovered by ethanol precipitation, resuspended in water, and used as template for DNA synthesis.

First-strand synthesis was performed using the CEVd-specific primer (CEVd-11) (CGCCCGGGGAAACCTGGAGGAAGTCG) complementary to positions 92 to 117 of CEVd-A (33) with modifications (changing the first nucleotides from UC to $\mathrm{CG}$ ), and reverse transcriptase Superscript I (Invitrogen). Primers CEVd-11 and CEVd-12 (CGCCCGGGGATCCCTGAAGGAYTT) ( $\mathrm{Y}$ corresponding to basis $\mathrm{C}$ or $\mathrm{T}$, with modifications similar to CEVd-11) homologous to basis 78 to 99 of CEVd-A (33) were used for second-strand synthesis and PCR amplification in a buffer containing $1 \mathrm{mM} \mathrm{MgCl} 2,0.25 \mathrm{mM}$ dNTPs, $0.5 \mu \mathrm{M}$ each primer, and $1 \mathrm{U}$ of Taq DNA polymerase. PCR parameters consisted of 35 cycles of $94^{\circ} \mathrm{C}$ for $40 \mathrm{~s}, 60^{\circ} \mathrm{C}$ for $40 \mathrm{~s}$, and $72^{\circ} \mathrm{C}$ for $1 \mathrm{~min}$, with a final extension at $72^{\circ} \mathrm{C}$ for $5 \mathrm{~min}$. Primerdirected selection was minimized because both primers correspond to a conserved sequence in the upper strand of the central conserved region (CCR).

Reverse-transcriptase (RT)-PCR products were analyzed in $2 \%$ agarose gels to verify the presence of a single DNA band of the expected size of CEVd and to molecular hybridization against a CEVd specific probe. The purified DNA was ligated into pGEM vector (Promega) and recombinant plasmids from transformed by heat shock. Escherichia coli-competent cells (25) were subjected to restriction analysis with $\mathrm{NcoI}$ and SalI restriction enzymes at $37^{\circ} \mathrm{C}$ overnight to verify the presence of an insert of the expected size.

Single-strand conformation polymorphism analysis. Cloned viroid double-stranded (ds)DNAs were recovered from the plasmids by PCR amplification using the same conditions described above. The PCR product $(3 \mu \mathrm{l})$ was mixed with $27 \mu \mathrm{l}$ of the denaturing solution ( $90 \%$ formamide, $25 \mathrm{mM}$ EDTA, $0.05 \%$ xylenecyanole, and $0.05 \%$ bromophenol blue), heated for $10 \mathrm{~min}$ at $100^{\circ} \mathrm{C}$, and chilled on ice. Denatured DNA was subjected to $14 \%$
PAGE (8.5-by-7.0-by-0.1-cm gels) in TBE buffer ( $89 \mathrm{mM}$ Trisborate and $2 \mathrm{mM}$ EDTA, $\mathrm{pH} 8.3$ ) at $200 \mathrm{~V}$ constant voltage for $16 \mathrm{~h}$. Under these conditions, the partially denatured dsDNA migrates as two or more single-stranded DNAs (hDNA and cDNA) homologous and complementary to the viroid sequence, respectively (20). The DNA bands were visualized by silver staining (12).

Sequencing and statistical analysis. Cloned CEVd DNAs were sequenced with the ABI PRISM DNA sequencer 377 (Perkin Elmer). Alignment of multiple sequences was performed using the program Clustal W (31). Secondary structure analyses were obtained with the MFOLD program (circular version) from the GCG package (35) and with the RNAviz program (4).

Nucleotide distances were estimated considering alignment gaps and using the Jukes and Cantor's method (13) for correction of superimposed substitutions with the MEGA 3.1 program (14). A phylogenetic tree was obtained with the neighbor-joining method (24) using the MEGA 3.1 program (14,23).

Synthesis of dimeric CEVd transcript sequences and infectivity assays. In order to obtain infectious single sequence variants, dimeric transcripts were obtained as follows. Plasmids containing monomeric CEVd-DNAs were used as template for PCR amplification. Monomeric viroid-DNA inserts were recovered as blunt-end products with the CEVd-specific primers CEVd-11 and CEVd-12 in a buffer containing $2 \mathrm{mM} \mathrm{MgSO}_{4}$, $0.13 \mathrm{mM}$ dNTPs, $0.5 \mu \mathrm{M}$ each primer, and $1 \mathrm{U}$ of Pwo DNA polymerase (Roche) using the same PCR parameters described above. The DNA products were phosphorylated using $10 \mathrm{mM}$ ATP and $0.3 \mathrm{U}$ of T4 DNA Kinase (Pharmacia), and were subjected to a ligation reaction with $2 \mathrm{U}$ of T4 ligase (Gibco) at $14^{\circ} \mathrm{C}$ for $16 \mathrm{~h}$. The dimeric molecules were purified from $2 \%$ agarose gels and were ligated into the EcoRV site of the pBS vector and transformed into E. coli-competent cells. Plasmids from transformed cells were subjected to restriction and sequence analysis to verify the correct tandem orientation of the dimeric inserts.

In order to obtain dimeric transcripts, plasmids containing dimeric inserts with correct tandem orientation were linealized with EcoRI or $X b a I$ restriction enzymes. Linealized plasmids were used in a transcription reaction with $1 \mathrm{mM}$ each NTP, $1 \mathrm{mM}$ dithiothreitol, and $50 \mathrm{U}$ of T3- or T7-RNA polymerase (Gibco) at $37^{\circ} \mathrm{C}$ for $2 \mathrm{~h}$ and at $65^{\circ} \mathrm{C}$ for $5 \mathrm{~min}$ to obtain a dimeric RNA homologous to the viroid sequence. Products were recovered by ethanol precipitation and analyzed by electrophoresis to verify the presence of transcripts.

Three broad bean plants and four tomato (Lycopersicon esculentum Mill.) cv. Rutgers seedlings were slash inoculated with RNA dimeric transcripts $(1 \mu \mathrm{g}$ in $50 \mathrm{mM}$ phosphate buffer, $\mathrm{pH}$ 8.5 , per plant). The inoculated plants were kept in the greenhouse at $25^{\circ} \mathrm{C}$ for at least 9 months. Infection was assessed by Northern blot hybridization every 3 months.

\section{RESULTS}

Infectivity and symptom expression of broad bean plants inoculated with CEVd-i and CEVd-f. Nucleic acid extracts from broad bean plants infected with CEVd-i or CEVd-f were used to inoculate broad bean seedlings. Three months after inoculation, plants inoculated with CEVd-f were stunted, whereas those inoculated with CEVd-i remained symptomless (Fig. 1A). Infection with CEVd-f was confirmed by sPAGE analysis and silver staining (Fig. 1B), whereas infection with CEVd-i could be assessed only by Northern blot hybridization (Fig. 1C), CEVd-i being present at very low titers only.

Genetic structure and diversity of CEVd-i, CEVd-t, and CEVd-f. When purified viroid preparations were used as templates for RT-PCR amplification, monomeric CEVd-DNA products of the expected size were recovered. Single-strand conformation polymorphism (SSCP) analysis of a selection of clones (35 of 
CEVd-i, 20 of CEVd-t, and 38 of CEVd-f ) revealed the presence of different SSCP electrophoretic patterns or haplotypes (Fig. 2). Under these conditions of electrophoresis and denaturation, the partially denatured dsDNA migrates as two or more single-stranded DNAs (hDNA and cDNA) homologous and complementary to the viroid sequence, respectively (20). Because the migration of the homologous DNA and complementary DNA strands depends on the sequence of nucleotides and, therefore, on their conformation, the different SSCP profiles indicated the existence of different sequence variants.

The SSCP patterns of CEVd-i were all different, suggesting a heterogeneous population in which no dominant haplotype could be identified (Fig. 2A). Sequencing of 20 clones randomly selected from this population confirmed that all the sequences were different. Alignment of these variants with the class A and class B reference sequences defined by Visvader and Symons (34) showed that three sequence variants (CEVd-i-18, CEVd-i-19, and CEVd-i-20) were highly homologous (97.9 to $99.2 \%$ identity) to class B and contained the signature characteristic of this class in the $\mathrm{P}$ and $\mathrm{V}$ domains, whereas the other 17 variants were homologous to class A (96.5 to $97.6 \%$ identity). The neighbor-joining phylogenetic tree produced by the MEGA 3.1 program (14) confirmed that CEVd-i-18, CEVd-i-19, and CEVd-i-20 were closely related to class $\mathrm{B}$ and two variants (CEVd-i-1 and CEVd-i-2) were related to class $\mathrm{A}$, whereas the remaining variants clustered outside of the class A and class B groups (Fig. 3). The nucleotide diversity estimated from the nucleotide distances of this CEVd-i population was $0.026 \pm 0.004$ (Table 1 ). In the CEVd-i population, two of the changes defined by Fagoaga et al. (6) $(\mathrm{A} \rightarrow \mathrm{C}$ in position 263 and $U \rightarrow A$ in position 234) were found in all the variants, whereas the change $\mathrm{C} \rightarrow \mathrm{U}$ in position 232 was found only in the CEVd-i variants homologous to the class B reference sequence. The predicted minimum free energy secondary structure of all CEVd-i variants (except variants homologous to class $\mathrm{B}$ and CEVd-i-1) was a typical rod-like structure. All CEVd-i sequences homologous to class $\mathrm{B}$ and $\mathrm{CEVd}-\mathrm{i}-1$ presented a branched structure in the $\mathrm{T}_{\mathrm{L}}$ domain (Fig. 4).

The SSCP patterns of CEVd-t were less heterogeneous than those of CEVd-i. Analysis of 20 clones showed 15 different haplotypes. Four haplotypes were represented more than once, while the remaining were represented by a single clone (Fig. 2B). Sequencing of 20 clones confirmed these observations. The alignment of the sequence variants with the class A and class B reference sequences showed that all of them were highly homologous
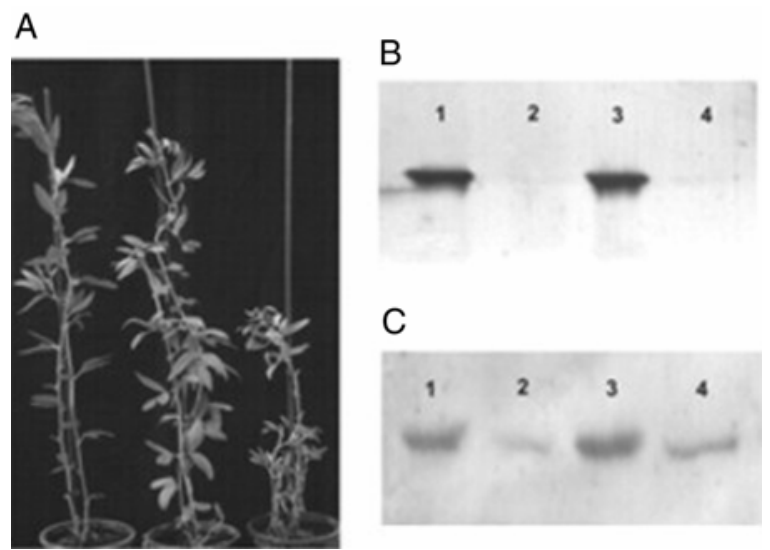

Fig. 1. A, Healthy and Citrus exocortis viroid (CEVd)-infected broad-bean plants: uninoculated control (left), plants infected with CEVd-i (center) and with CEVd-f (right). B, Sequential polyacrylamide gel electrophoresis (sPAGE) analysis of inoculated broad bean plants. C, Northern blot hybridization with digoxigenin (DIG)-CEVd probe of the same samples subjected to sPAGE and electrotransferred to a membrane. Lane 1, Positive CEVd control; lanes 2 and 4, plants inoculated with CEVd-i; and lane 3, plant inoculated with CEVd-f.
(97.8 to $98.6 \%$ identity) to class A and contained the signature characteristic of this class in the $\mathrm{P}$ and $\mathrm{V}$ domains. The nucleotide diversity estimated from the nucleotide distances of this CEVd-t population was $0.007 \pm 0.002$ (Table 1). The minimum free energy secondary structure of all CEVd-t sequences was a typical rod-like structure (Fig. 4).

SSCP analysis of 38 CEVd-f clones showed six different electrophoretic patterns or haplotypes, two of which (CEVd-f-1 and CEVd-f-2) were represented by $28(73.7 \%)$ and $6(15.8 \%)$ clones, respectively; the other four haplotypes were represented by a single clone (Fig. 2C). Sequencing of 11 clones ( 4 for CEVd-f-1, 3 for CEVd-f-2, and 1 for rest of haplotypes) confirmed the exis-
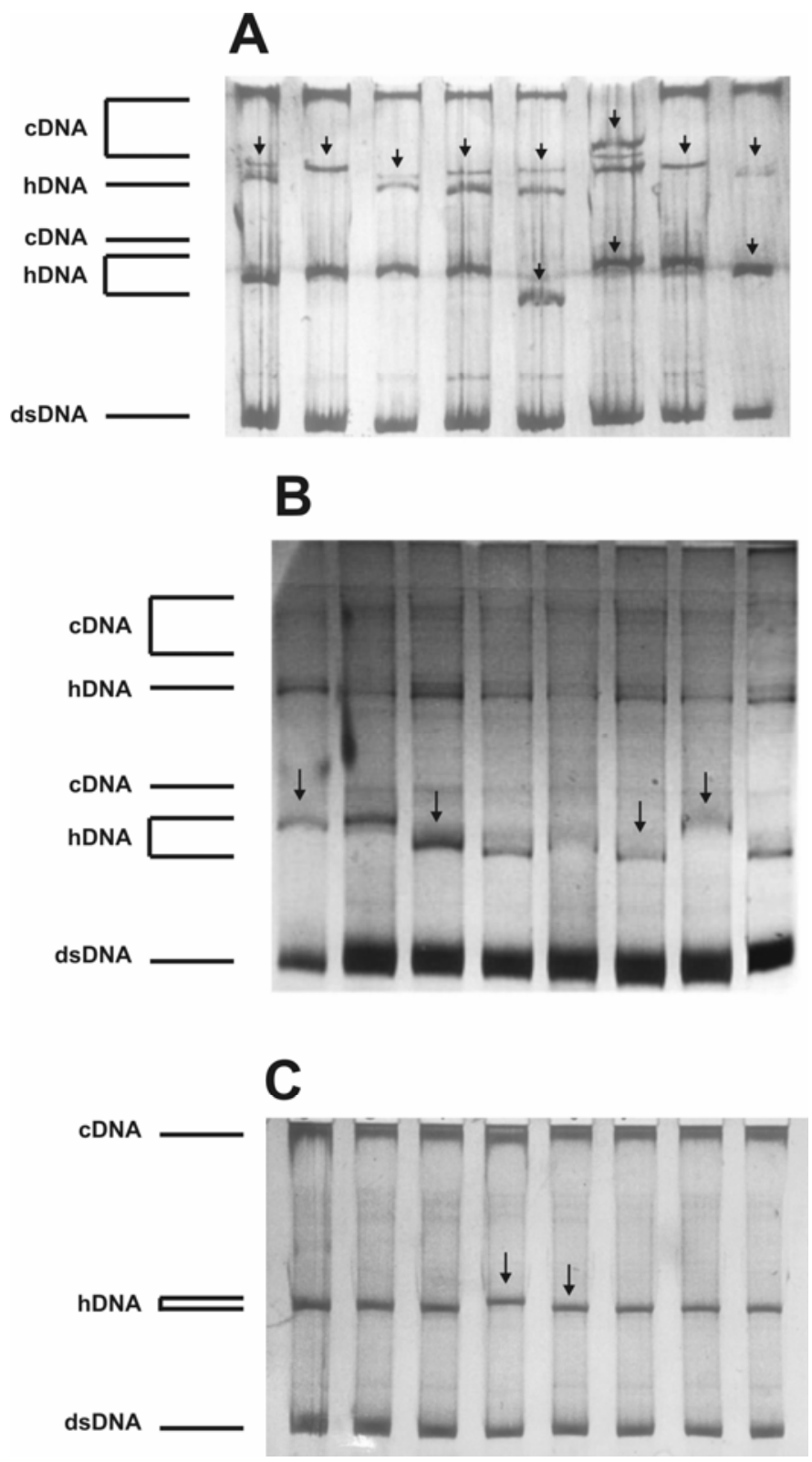

Fig. 2. Single-strand conformation polymorphism (SSCP) analysis of cloned full-length Citrus exocortis viroid (CEVd) sequences. A, Clones obtained from broad bean plants infected with CEVd-i with different electrophoretic patterns. B, Clones obtained from tomato plants infected with CEVd-t (CEVd-t was recovered from tomato plants inoculated with CEVd-i (broad bean $\rightarrow$ tomato), with four different electrophoretic patterns. C, Clones obtained from broad bean plants infected with CEVd-f (CEVd-f was recovered from broad bean plants inoculated with CEVd-t; broad bean $\rightarrow$ tomato $\rightarrow$ broad bean), with two different electrophoretic patterns. hDNA and cDNA are the DNA strands homologous and complementary to the CEVd sequence, respectively; dsDNA $=$ double-stranded DNA; and $\downarrow$ indicates different mobility patterns. 
tence of a predominant sequence variant. Sequence alignment showed that all of them were highly homologous (97.6 to $97.9 \%$ identity) to class A and contained the signature characteristic of this class in the $\mathrm{P}$ and $\mathrm{V}$ domains. The nucleotide diversity estimated from the nucleotide distances of this CEVd-f population was $0.001 \pm 0.001$ (Table 1 ). The minimum free energy secondary structure of all CEVd-f variants showed a branched structure in the $\mathrm{T}_{\mathrm{L}}$ domain (Fig. 4).

It is significant to mention that, of the five nucleotide changes described as "tomato signatures" by Semancik et al. (28), only one ( $\mathrm{U} \rightarrow \mathrm{A}$ in position 277 ) was conserved in all the sequences of the CEVd-t population, whereas the changes $\mathrm{G} \rightarrow \mathrm{A}$ in position 50 and $U \rightarrow G$ in position 265 were present in nine and four haplotypes, respectively. None of these changes were found in the CEVd-f variants. In addition, the four changes $(\mathrm{U} \rightarrow \mathrm{C}$ in position $232, \mathrm{G} \rightarrow \mathrm{C}$ in position $289, \mathrm{U} \rightarrow \mathrm{A}$ in position 287 , and $-\mathrm{G}$ in position 264) reported by Fagoaga et al. (6) in the lower strand of the $\mathrm{C}$ domain were found in all the variants of CEVd-t and CEVd-f.

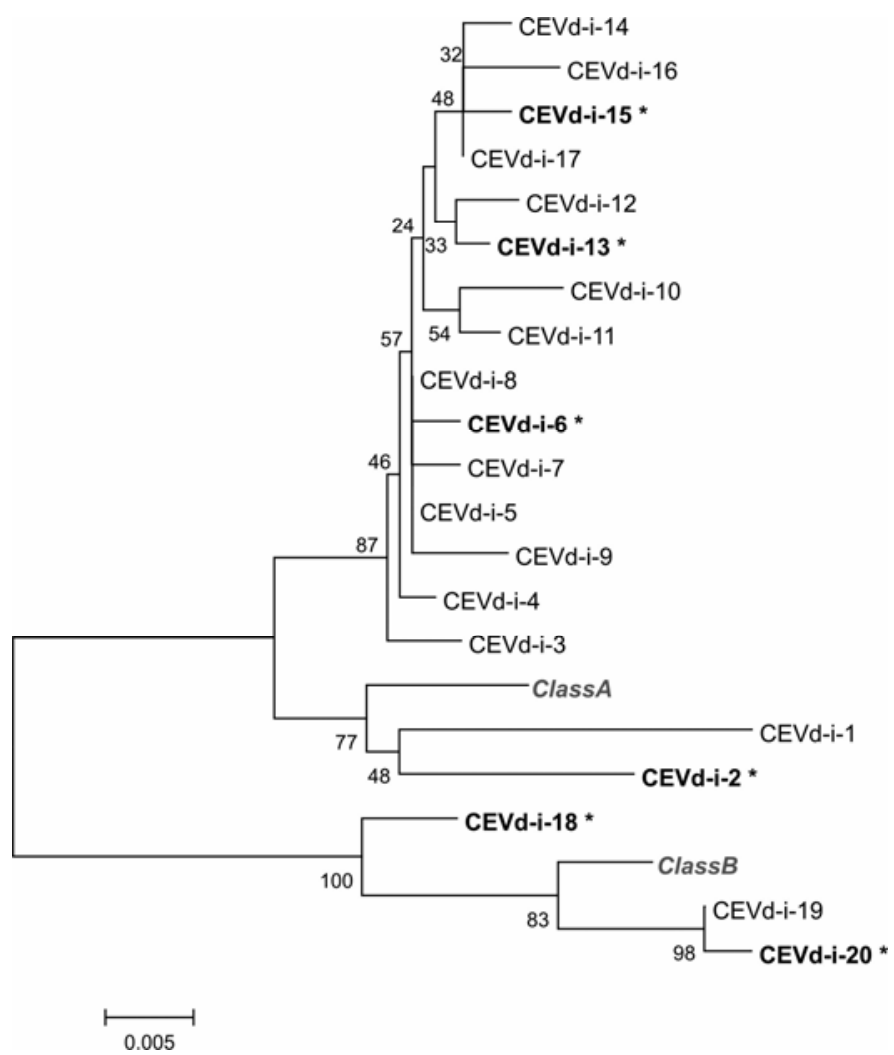

Fig. 3. Neighbor-joining phylogenetic tree obtained with the sequences recovered from Citrus exocortis viroid (CEVd)-i by MEGA 3.1 program (14) with 10,000 replications of bootstrap test. Nucleotide distances were estimated using the Jukes and Cantor's method (13).The reference sequences of class A and class B also were included (34). An asterisk (*) indicates the sequence variants selected to conduct infectivity assays.
The nucleotide diversity between CEVd-i, CEVd-t, and CEVd-f was estimated (Table 1). Results showed that nucleotide diversity between CEVd-i and CEVd-t populations was higher than that between others, and that nucleotide diversity between CEVd-f and CEVd-t populations was the lowest.

Infectivity assay of individual haplotypes and genetic structure and diversity of their progenies. To determine the biological properties associated with the variants clustered together in the phylogenetic tree, six variants of CEVd-i (Fig. 3, *: CEVd-i-2, CEVd-i-6, CEVd-i-13, CEVd-i-15, CEVd-i-18, and CEVd-i-20) representing the major clusters and a dominant variant of CEVd-f (CEVd-f-1) were selected to conduct infectivity assays in broad bean and tomato plants. Six months postinoculation with dimeric transcripts, three variants (CEVd-i-15, CEVd-i-20, and CEVd-f-1) were infectious in broad bean and two variants (CEVd-i-2 and CEVd-i-20) were infectious in tomato (Table 2), but all of them were symptomless. The two variants that infected tomato had a change $(\mathrm{G} \rightarrow \mathrm{A})$ in position 50 , which is typical of other CEVd sequences reported from tomato $(6,28,34)$. CEVd-i-20 was the only variant that infected both hosts. Unexpectedly, no infectivity was achieved in broad bean with four variants recovered from CEVd-i (CEVd-i-2, CEVd-i-6, CEVd-i13, and CEVd-i-18).

In order to characterize the progeny generated in broad bean by the three infectious variants (CEVd-i-15, CEVd-i-20, and CEVdf-1), nucleic acid extracts from infected but symptomless plants were used as templates for RT-PCR amplification. Products were ligated into pGEM vectors and a selection of clones was analyzed by SSCP. Nucleotide diversity within and between these populations are indicated in Table 1 and the number of SSCP profiles and the sequence variants identified are summarized in Table 2.

\section{DISCUSSION}

Fagoaga et al. (6) identified CEVd as a natural infection in broad bean plants, a species that had not been reported previously as a viroid host. Transmission assays caused important changes in the biological properties of this CEVd isolate, and these changes were not restored after back transmission to the original host. The modifications of the biological properties resulting from transmission to tomato were associated with changes of the consensus sequences determined by sequencing the RT-PCR products from infected broad bean and tomato (6).

The results of the present study show that the original CEVd source recovered from field-grown broad bean plants (CEVd-i) contained a heterogeneous population of sequence variants (nucleotide diversity of CEVd-i $=0.026$ ), some of which were phylogenetically related to class A, others to class B (34) and, unexpectedly, a number of variants were distant from both of these two groups. The heterogeneity of CEVd-i also explains the difficulties encountered in defining the consensus sequence of this isolate (C. Fagoaga, personal communication). Whether the unusual heterogeneity of CEVd-i is due to the peculiar composition of the unknown inoculum source or the result of multiple infections cannot be ascertained in the present study. Transmission to

TABLE 1. Nucleotide diversity within and between Citrus exocortis viroid (CEVd) populations

\begin{tabular}{|c|c|c|c|c|c|c|}
\hline & \multirow{2}{*}{$\begin{array}{c}\text { CEVd isolate from } \\
\text { broad bean } \\
\text { CEVd-i }\end{array}$} & \multicolumn{2}{|c|}{$\begin{array}{l}\text { CEVd recovered after transmission } \\
\text { to alternate hosts }\end{array}$} & \multicolumn{3}{|c|}{$\begin{array}{l}\text { Populations generated in broad bean plants inoculated } \\
\text { with individual sequence variants } \mathrm{s}^{\mathrm{a}}\end{array}$} \\
\hline & & CEVd-t & CEVd-f & CEVd-i-15 & CEVd-i-20 & CEVd-f-1 \\
\hline CEVd-i & $0.026 \pm 0.004$ & $0.025 \pm 0.005$ & $0.018 \pm 0.003$ & $0.021 \pm 0.003$ & $0.016 \pm 0.002$ & $0.025 \pm 0.004$ \\
\hline CEVd-f & $\ldots$ & $\ldots$ & $0.001 \pm 0.001$ & $0.010 \pm 0.004$ & $0.005 \pm 0.003$ & $0.013 \pm 0.004$ \\
\hline CEVd-i-15 & $\ldots$ & $\ldots$ & $\ldots$ & $0.007 \pm 0.003$ & $0.007 \pm 0.003$ & $0.010 \pm 0.003$ \\
\hline CEVd-i-20 & $\ldots$ & $\ldots$ & $\ldots$ & $\ldots$ & $0.004 \pm 0.001$ & $0.012 \pm 0.004$ \\
\hline
\end{tabular}

${ }^{a} \mathrm{CEVd}$ populations generated after inoculation with sequence variants CEVd-i-15, CEVd-i-20, and CEVd-f-1. 
tomato resulted in a more homogeneous population of sequence variants (nucleotide diversity of CEVd-t $=0.007$ ), all of them related to class $\mathrm{A}$. The population of $\mathrm{CEVd}$ variants remained homogeneous (nucleotide diversity of CEVd-f $=0.001$ ) after back transmission to broad bean. In fact, the nucleotide diversity value between populations was the highest between CEVd-i and CEVd$\mathrm{t}$ (0.025), and the lowest between CEVd-f and CEVd-t (0.011), indicating that the last two populations were actually similar. Some of the observed changes may have resulted from errors produced during PCR amplification using Taq DNA polymerase. However, errors produced by Taq DNA polymerase cannot account for the differences in heterogeneity among CEVd-i, CEVd-t, and CEVd-f. In fact, in a previous study, no mutants were found in 30 clones obtained after PCR using as a template a single cDNA-CEVd clone (20).

These results suggest that tomato acted as a bottleneck favoring those sequence variants related to class $\mathrm{A}$ and displacing the others in an irreversible manner. It could be argued that the apparent high fitness of class A variants in tomato would be detrimental for their survival. However, given the relatively short vegetative period of tomato compared with perennial hosts such as grapevine and citrus, such perennial hosts that sustain CEVd replication as latent infections probably have played a major role for the widespread and survival of this putative pathogen.

Infectivity assays revealed that not all the variants were able to infect broad bean or tomato. The lack of infectivity observed
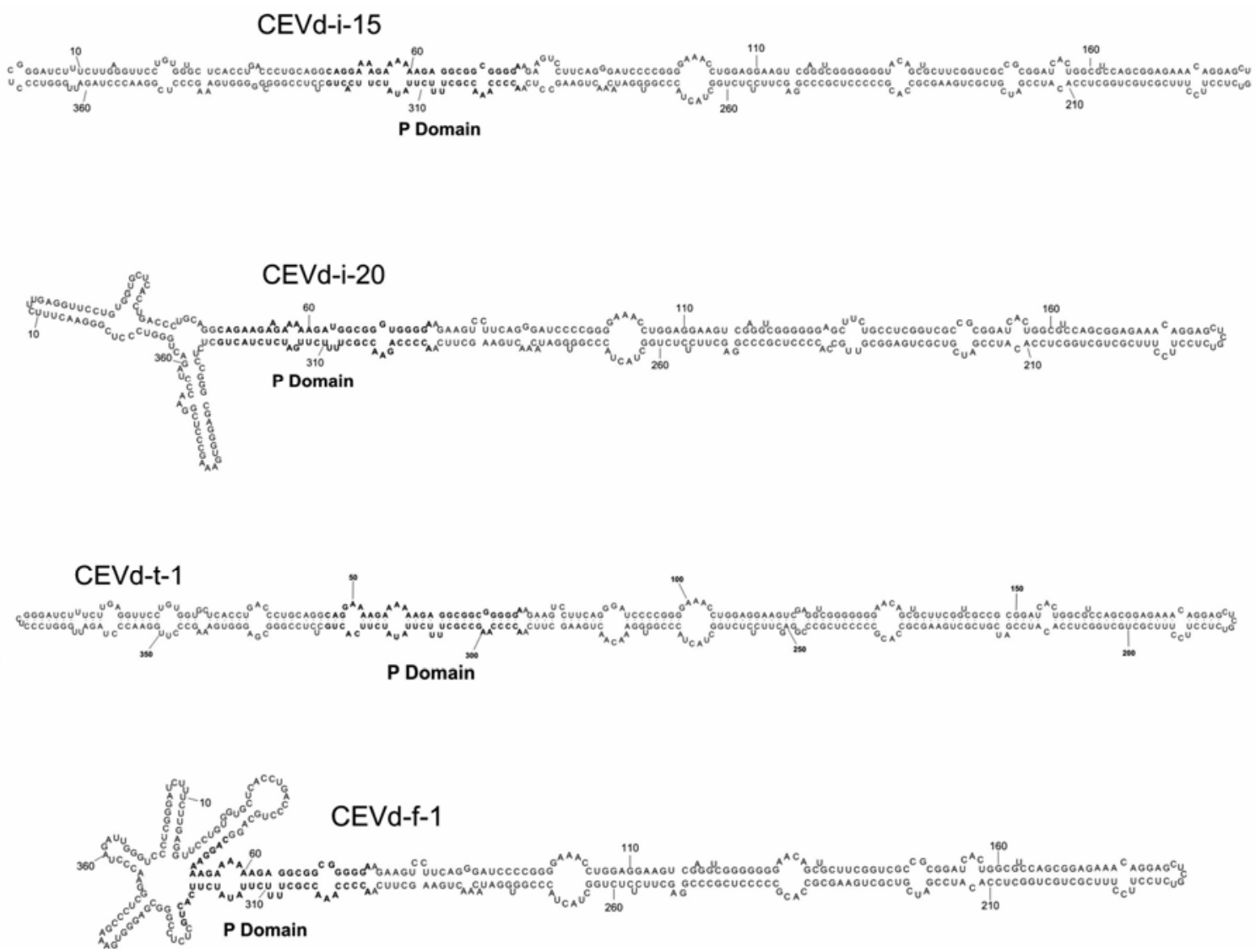

Fig. 4. Predicted minimum free energy secondary structures of sequence variants recovered from Citrus exocortis viroid (CEVd)-i, CEVd-t, and CEVd-f.

TABLE 2. Infectivity and progeny analysis of selected sequence variants

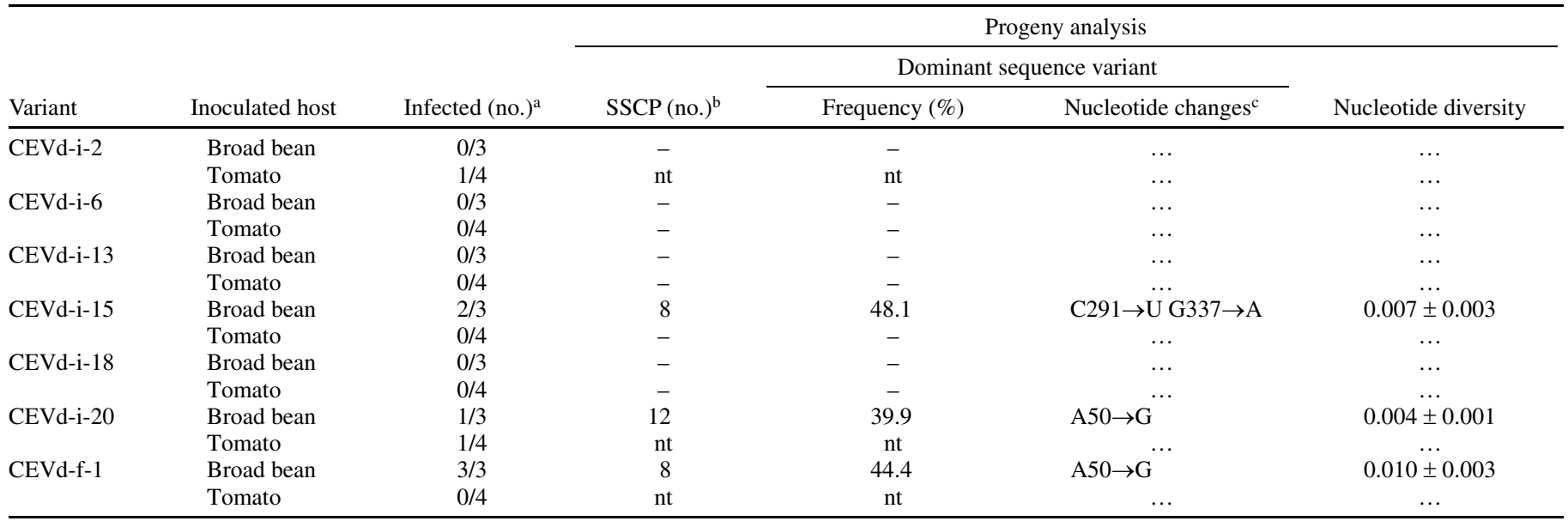

${ }^{a}$ Number of infected plants/number of inoculated plants.

${ }^{\mathrm{b}}$ Single-strand conformation polymorphism (SSCP) profiles; $\mathrm{nt}=$ not tested and $-=$ no infected plants available.

${ }^{c}$ Nucleotide changes found in the dominant sequence of the progeny variant when compared with the inoculated variant. 
when four variants recovered from broad bean (CEVd-i) were inoculated in broad bean suggests that they probably were generated de novo in this host as a result of the replication of other infectious variants in the absence of proofreading mechanisms. A similar situation also was described in citron inoculated with certain variants recovered from the same host (9).

The experimental transmission of pathogens to alternative hosts is a common practice in plant pathology and, according to the results of the present study, such strategies should be regarded with caution. In fact, transmission to tomato has been widely used for the molecular and biological characterizations of CEVd and isolates of Potato spindle tuber viroid (PSTVd) $(6,11,18,19$, 28,30 ); therefore, the results obtained may not reflect the characteristics of the isolate studied and, more importantly, they should not be extrapolated to other hosts.

The host effect on the heterogeneity of CEVd also has been illustrated recently in experiments with citrus, which show that infected trifoliate orange, a sensitive species presenting symptoms of stunting, bark scaling, and stem blotching, contained a population of variants with low nucleotide diversity and a clearly predominant haplotype. Conversely, sour orange, a symptomless host, contained a population of variants with a higher nucleotide diversity in which no dominant haplotype could be identified (3). As in the case of broad bean, symptomless citrus hosts appear to sustain the replication of CEVd as latent infections, thereby acting as reservoirs of viroid biodiversity. From the epidemiological point of view, these reservoirs, although unnoticed in symptomless plants, may be readily transmissible to other hosts. In the present study, the results of the transmission assays conducted with single variants illustrate the fact that different host species may have different affinities for specific CEVd sequence variants. Therefore, the existence of hosts containing heterogeneous populations of CEVd variants provide the best inoculum source in terms of its potential to infect a broad range of putative hosts.

The impact of symptomless hosts as reservoirs of potential pathogens, once transmission to sensitive hosts occurs, can be readily illustrated in the case of citrus viroids that were widely distributed but remained unnoticed in commercial citrus grafted on sour orange. CEVd was identified later as a pathogenic agent, once other species, such as trifoliate orange, its hybrids Carrizo and Troyer citranges, and Rangpur lime, were assayed as alternate rootstocks $(1,2,7,16)$. A similar situation occurred in Holland when the "cucumber pale disease" was identified in greenhousegrown cucumbers and later found to be caused by Hop stunt viroid (HSVd), one of the most widely spread viroids, that probably had been unwillingly introduced as a contaminant from an unknown source (32).

The identification of broad bean and other vegetable crop species (5) as natural hosts for CEVd indicates that such viroid reservoirs may occur more widely than initially anticipated. How the field-grown broad bean plants, a seed-propagated annual crop, became infected remains unknown. Even though CEVd apparently is not seed transmitted in citrus, nothing is known about its vertical transmission in other plant species. Because PSTVd, HSVd, and other viroids of the Pospiviroidae family actually are seed transmissible, the permanence of CEVd in vegetable crops should rely on vertical transmission, a strategy that has likely played a role in the perpetuation of viroids from their origin in a precellular world until now.

\section{ACKNOWLEDGMENTS}

M. Gandía was recipient of an IVIA fellowship. The work was supported by grants RTA01-119 and AGL2005-01469 from the Ministerio de Ciencia y Tecnología (Spain). We thank J. M. Bové for critical reading of the manuscript, C. Vives for her help with submission sequences, and R. Carbó for technical assistance.

\section{LITERATURE CITED}

1. Benton, R. J., Bowman, F. T., Fraser, L., and Kebby, R. G. 1949. Selection of citrus budwood to control scaly butt in trifoliata rootstock. Agric. Gaz. N. S. Wales 60:31-34.

2. Benton, R. J., Bowman, F. T., Fraser, L., and Kebby, R. G. 1950. Stunting and scaly butt associated with Poncirus trifoliata rootstock. N. S. Wales Dep. Agric. Sci. Bull. 70:1-20.

3. Bernad, L., Gandía, M., and Duran-Vila, N. 2006. Host effect on the genetic variability of Citrus exocortis viroid (CEVd). Pages 291-300 in: Proc. 16th IOCV Conf. IOCV, Riverside, CA.

4. De Rijk, P., and De Wachter, R. 1997. RnaViz, a program for the visualization of RNA secondary structure. Nucleic Acids Res. 25(22):4679-4684.

5. Fagoaga, C., and Duran-Vila, N. 1996. Naturally occurring variants of citrus exocortis viroid in vegetable crops. Plant Pathol. 45:45-53.

6. Fagoaga, C., Semancik, J. S., and Duran-Vila, N. 1995. A citrus exocortis viroid variant from broad bean (Vicia faba L.): Infectivity and pathogenesis. J. Gen. Virol. 76:2271-2277.

7. Fawcett, H. S., and Klotz, L. J. 1948. Exocortis on trifoliate orange. Citrus Leaves 28:8.

8. Flores, R., Duran-Vila, N., Pallás, V., and Semancik, J. S. 1985. Detection of viroid and viroid-like RNAs from grapevine. J. Gen. Virol. 66:20952102.

9. Gandía, M., Rubio, L., Palacio, A., and Duran-Vila, N. 2005. Genetic variation and population structure of an isolate of Citrus exocortis viroid $(\mathrm{CEVd})$ and of the progenies of two infectious sequences variants. Arch. Virol. 150:1945-1957.

10. García-Arenal, F., Pallás, V., and Flores, R. 1987. The sequence of a viroid from grapevine closely related to severe isolates of citrus exocortis viroid. Nucleic Acids Res. 15:4203-4210.

11. Gast, F. U., Kempe, D., Spieker, R. L., and Sänger, H. L. 1996. Secondary structure probing of potato spindle tuber viroid (PSTVd) and sequence comparison with other small pathogenic RNA replicons provides evidence for central non-canonical base pairs, large A-rich loops, and a terminal branch. J. Mol. Biol. 262:652-670.

12. Igloi, G. L. 1983. Silver stain for the detection of nanogram amounts of tRNA following two-dimensional electrophoresis. Anal. Biochem. 134:184-188.

13. Jukes, T. H., and Cantor, C. R. 1969. Evolution of protein molecules. Pages 21-132 in: Mammalian Protein Metabolism. H. N. Munro, ed. Academic Press, New York.

14. Kumar, S., Tamura, K., and Nei, M. 2004. MEGA3: Integrated software for molecular evolutionary genetics analysis and sequence alignment. Brief. Bioinf. 5:150-163.

15. Mishra, M. D., Hammond, R. W., Owens, R. A., Smith, D. R., and Diener, T. O. 1991. Indian bunchy top disease of tomato plants is caused by a distinct strain of citrus exocortis viroid. J. Gen. Virol. 72:1781-1785.

16. Moreira, S. 1955. Sintomas de "exocortis" em limoneiro cravo. Bragantia 14:19-21.

17. Morris, T. J., and Wright, N. S. 1975. Detection on polyacrylamide gel of a diagnostic nucleic acid from tissue infected with potato spindle tuber viroid. Am. Potato J. 52:57-63.

18. Owens, R. A., Steger, G., Hu, Y., Fels, A., Hammond, R. A., and Riesner, D. 1996. RNA structural features responsible for potato spindle tuber viroid pathogenicity. Virology 222:144-158.

19. Owens, R. A., Thompson, S. M., and Kramer, M. 2003. Identification of neutral mutants surrounding two naturally occurring variants of potato spindle tuber viroid. J. Gen. Virol. 84:751-756.

20. Palacio, A., and Duran-Vila, N. 1999. Single-strand conformation polymorphism (SSCP) analysis as a tool for viroid characterisation. J. Virol. Methods 77:27-36.

21. Palacio, A., Foissac, X., and Duran-Vila, N. 2000. Indexing of citrus viroids by imprint hybridisation. Eur. J. Plant Pathol. 105:897-903.

22. Rivera-Bustamante, R. F., Gin, R., and Semancik, J. S. 1986. Enhanced resolution of circular and linear molecular forms of viroid and viroid-like RNA by electrophoresis in a discontinuous-pH system. Anal. Biochem. 156:91-95.

23. Rozas, J., and Rozas, R. 1999. DNASP version 3: An integrated program for molecular population genetic and molecular evolution analysis. Bioinformatics 15:174-175.

24. Saitou, N., and Nei, M. 1987. The neighbor-joining method: A new method for reconstructing phylogenetic trees. Mol. Biol. Evol. 4:406-425.

25. Sambrook, J., Fristch, E. F., and Maniatis, T. 1989. Molecular Cloning: A Laboratory Manual. Cold Spring Harbor Laboratory Press, Cold Spring Harbor, NY.

26. Sänger, H. L., Ramm, K., Domdey, H., Gross, H. J., Henco, K., and Riesner, D. 1979. Conversion of circular viroid molecules to linear strands. FEBS Lett. 99:117-121. 
27. Semancik, J. S., Morris, T. J., Weathers, L. G., Rordorf, G. F., and Kearns, D. R. 1975. Physical properties of a minimal infectious RNA (viroid) associated with the exocortis disease. Virology 63:160-167.

28. Semancik, J. S., Szychowski, J. A., Rakowski, A. G., and Symons, R. H. 1993. Isolates of citrus exocortis viroid recovered by host and tissue selection. J. Gen. Virol. 74:2427-2436.

29. Semancik, J. S., and Weathers, L. G. 1972. Exocortis virus: An infectious free-nucleic acid plant virus with unusual properties. Virology 47:456-466.

30. Szychowski, J. A., Vidalakis, G., and Semancik, J. S. 2005. Host-directed processing of Citrus exocortis viroid. J. Gen. Virol. 86:473-477.

31. Thompson, J. D., Higgins, D. G., and Gibson, T. J. 1994. CLUSTAL W. Improving the sensitivity of progressive multiple sequences alignment through sequence weighting, positions-specific gap penalties and weight matrix choice. Nucleic Acids Res. 22:4673-4680.
32. Van Dorst, H. J. M., and Peters, D. 1974. Some biological observations on pale fruit, a viroid-incited disease of cucumber. Neth. J. Plant Pathol. 80:85-96.

33. Visvader, J. E., Gould, A. R., Bruening, G. E., and Symons, R. H. 1982. Citrus exocortis viroid: nucleotide sequence and secondary structure of an Australian isolate. FEBS Lett. 137(2):288-292.

34. Visvader, J. E., and Symons, R. H. 1985. Eleven new sequence variants of citrus exocortis viroid and the correlation of sequence with pathogenicity. Nucleic Acids Res. 13(8):2907-2920.

35. Zuker, M., Mathews, D. H., and Turner, D. H. 1999. Algorithms and Thermodynamics for RNA Secondary Structure Prediction: A Practical Guide in RNA Biochemistry and Biotechnology, J. Barciszewski and B. F. C. Clark, eds. NATO ASI Series, Kluwer Academic Publishers, Dordrecht, The Netherlands. 